\title{
PERCEIVED STIGMA IN FUNCTIONAL SOMATIC SYNDROMES AND COMPARABLE MEDICAL CONDITIONS
}

\author{
Karl J. Looper, MD \\ Department of Psychiatry, Faculty of Medicine \\ McGill University, Montreal
}

March 2002

A thesis submitted to the Faculty of Graduate Studies and Research in partial fulfillment of the requirements for the degree of: Master of Science in Psychiatry

Sir Mortimer B. Davis - Jewish General Hospital

Department of Psychiatry, Office A-540

3755 Chemin de la Côte des Neiges, Montreal, QC, H3T 1E2

tel: 340-8222 (5882), fax: 340-8126, email: karl.looper@mcgill.ca 
Acquisitions and Bibliographic Services

305 Wellingron Street OHaw ON K1A ONA

The author has granted a nonexclusive licence allowing the National Library of Canada to reproduce, loan, distribute or sell copies of this thesis in microform, paper or electronic formats.
L'auteur a accordé une licence non exchusive permettant à la Bibliotheque nationale du Canada de reproduire, prêter, distribuer ou vendre des copies de cette thèse sous la forme de microfiche/film, de reproduction sur papier ou sur format électronique.

L'auteur conserve la proprièté du droit d'auteur qui protège cette thèse. Ni la thèse ni des extraits substantiels de celle-ci ne doivent être imprimés ou autrement reproduits sans son autorisation. 
TABLE OF CONTENTS

TABLE OF CONTENTS

LIST OF FIGURES AND TABLES 3

$\begin{array}{ll}\text { ABSTRACT } & 4\end{array}$

RÉSUMÉ

INTRODUCTION 6

REVIEW OF LITERATURE: Functional Somatic Syndromes 7-11

Stigma $11-18$

$\begin{array}{ll}\text { OBJECTIVES } & 19\end{array}$

$\begin{array}{ll}\text { HYPOTHESES } & 20\end{array}$

METHODS: Sample \& Procedures 21-22

$\begin{array}{lr}\text { Measures } & 22-24\end{array}$

$\begin{array}{ll}\text { Data Analysis } & 24-25\end{array}$

RESULTS: Characteristics of the Sample 26

Rates of Perceived Stigma 27-28

$\begin{array}{ll}\text { DISCUSSION } & 33-36\end{array}$

$\begin{array}{ll}\text { LIMITATIONS } & 37-38\end{array}$

$\begin{array}{ll}\text { CONCLUSION } & 39\end{array}$

$\begin{array}{ll}\text { ACKNOWLEDGEMENTS } & 40\end{array}$

$\begin{array}{ll}\text { REFERENCES } & 41-57\end{array}$

APPENDIX 1: Attitudes of Others Scale $\quad 58-59$

APPENDIX 2: SCL-90 Depression Sub-scale, modified 60 


\section{LIST OF FIGURES}

FIGURE 1: Stigma by diagnostic group

\section{LIST OF TABLES}

TABLE 1: Descriptive data for irritable bowel syndrome (IBS) and inflammatory bowel disease (IBD).

TABLE 2: Stepwise multiple linear regression, for the IBS and IBD group, with perceived stigma as the dependent variable.

TABLE 3: Descriptive data for fibromyalgia (FM) and rheumatoid arthritis (RA).

TABLE 4: Stepwise multiple linear regression, for the FM and RA group, with perceived stigma as the dependent variable.

TABLE 5: Descriptive data for chronic fatigue syndrome (CFS) and multiple sclerosis (MS).

TABLE 6: Stepwise multiple linear regression, for the CFS and MS group, with perceived stigma as the dependent variable. 


\begin{abstract}
Objective: To determine whether having a condition of unknown medical cause contributes to perceived stigma in individuals with functional somatic syndromes (FSS).

Methods: Subjects in three FSS groups, irritable bowel syndrome (IBS), fibromyalgia (FM), and chronic fatigue syndrome (CFS), were matched to medical control groups. Self-report measures were used to collect sociodemographic information, and rates of depression, physical functioning, and perceived stigma.

Results: Having the FSS was associated with perceived stigma in CFS compared to the medical control group, and remained an independent predictor when controlling for depression and physical functioning on multivariate analysis. These effects were not seen in FM or IBS compared to medical control groups.

Conclusions: The ambiguity of having a medically unexplained syndrome may contribute to perceived stigma in CFS. The absence of this effect in FM and IBS may reflect a greater acceptance of FM and IBS as medical conditions.
\end{abstract}




\section{RÉSUMÉ}

But : Déterminer si le fait d'être atteint d'un problème de santé dont la cause est médicalement inexpliquée contribue à la perception de stigmas chez des individus souffrant d'un syndrome somatique fonctionnel (SSF).

Méthode : Des sujets souffrant du syndrome de l'intestin irritable (SII), de fibromyalgie (FM) ou du syndrome de fatigue chronique (SFC), ont été pairés à des groupes contrôles médicaux. Les participants ont eux-mêmes rempli un questionnaire permettant d'obtenir des informations socio-démographiques, ainsi que les taux de dépression, de fonctionnement physique et de perception des stigmas.

Résultats : Le fait de souffrir d'un syndrome fonctionnel est associé à la perception de stigmas chez les patients souffrant du SFC comparativement au groupe contrôle, et est demeuré un prédicteur indépendant même quand les niveaux de dépresssion et de fonctionnement physique ont été contrôlés dans le cadre d'une analyse multivariée. Nous n'avons pas retrouvé d'effets semblables chez les participants souffrant de SII ou de FM comparativement aux groupes contrôles.

Conclusions : Le doute associé au fait de souffrir d'un syndrome médicalement inexpliqué peut contribuer à la perception de stigmas chez les SFC. L'absence de cet effet observé chez les SII et FM reflète peut-être une plus grande acceptation du SII et FM comme problèmes médicaux. 


\section{INTRODUCTION}

Functional somatic syndromes (FSS) are a group of conditions characterized by the presence of physical symptoms unexplained by any identifiable medical pathology. These include three conditions that are the focus of this thesis: chronic fatigue syndrome, fibromyalgia, and irritable bowel syndrome, but there are many other examples such as environmental sensitivity, chronic pelvic pain, and non-cardiac chest pain. Although they present as physical conditions, FSS have been closely associated with psychological symptoms and diagnoses. The ambiguity of their status as medical conditions has caused controversy within the medical community as well as in the general public. Patients with FSS report feeling a lack of validation of their experience of being physically ill, and stigmatized by the suggestion that their symptoms are caused by psychological factors. Patient advocacy groups have focussed their efforts on gaining greater acceptance of their illness as valid medical conditions, and obtaining the social benefits accorded to individuals with chronic medical illness and disability. This thesis deals with the issue of perceived stigma in FSS. The objective is to identify the perceived stigma due to the ambiguous diagnostic status of FSS by comparing rates of perceived stigma between three common FSS and similar medical conditions for which the diagnostic status is clearly accepted as medical. 


\section{REVIEW OF LITERATURE}

\section{FUNCTIONAL SOMATIC SYNDROMES}

The experience of physical symptoms in the absence of a diagnosed medical disease is a perplexing but common problem. In a study of primary care patients, 14 common physical symptoms accounted for $40 \%$ of patient visits. Of these, only $10 \%$ (of the $40 \%$ ) were found to have a physical cause (Kroenke et al, 1997). It is estimated that $25-50 \%$ of patients attending primary care physicians' offices present with medically unexplained or "functional" symptoms (Katon \& Walker, 1998). Functional somatic syndromes (FSS) refer to a category of illnesses characterized by particular constellations of medically unexplained symptoms. FSS are found in most areas of medicine, are usually chronic, and often appear similar to known medical diseases without the underlying pathology (Kirmayer, Looper \& Taillefer, 2002). Three of the most common FSS are the focus of this thesis: irritable bowel syndrome, fibromyalgia, and chronic fatigue syndrome.

Irritable Bowel Syndrome (IBS)

Irritable bowel is a syndrome of abdominal pain, and alteration of bowel habits (Drossman, Powell \& Sessions, 1977). An international commission of gastroenterology has proposed consensus criteria for the diagnosis of IBS (Thompson et al, 1989). This requires one of the following: 1) abdominal pain relieved with defecation and/or associated with a change in frequency or consistence of stools, or 2) disturbed defecation 
defined as altered stool frequency altered stool form, straining or urgency feeling of incomplete evacuation, or passage of mucus.

Bowel symptoms similar to those found in IBS are very common in the community, estimated as up to $20 \%$ of the population (Heaton et al, 1992; Jones \& Lydeared, 1992; Drossman et al, 1982; Sandler et al, 1984). Although only a minority of these seek help for this disturbance, IBS is the single most common diagnosis in gastroenterological practice (Harvey, Salih \& Read, 1983).

Elevated rates of depression and other psychiatric morbidity have been observed in IBS subjects compared to normal controls (Hislop, 1971; Lydiard et al., 1993; Sammons \& Karoly, 1987, Whitehead et al, 1980). Two studies have found no evidence of increased psychopathology among individuals with IBS in the community (Drossman et al., 1988; Whitehead et al., 1988). However, in both of these studies, IBS sufferers who sought medical help did show elevated levels of psychological distress, leading these authors to suggest that psychopathology may influence help-seeking behaviour rather than symptom development. Although the disability associated with IBS has not been well studied, there is evidence that patients with IBS have elevated help seeking (Talley, 1995), and lower quality of life and work productivity (Hahn et al, 1999) compared to the general population.

Fibromyalgia (FM)

Fibromyalgia or fibrositis is a syndrome of chronic musculoskeletal pains and stiffness of unknown etiology (Bennett, 1987). In addition, FM is identified by the presence of acute sensitivity to pressure over specific anatomical locations, termed tender points 
(Smythe, 1986). Various diagnostic criteria have been proposed that differ primarily in the number of tender points and in the significance of associated symptoms (Wolfe et al., 1985; Yunus et al., 1981). The American College of Rheumatology conducted a multicenter study of alternative diagnostic criteria to arrive at a consensus on the criteria that best differentiate fibromyalgia patients form other rheumatologic patients (Wolfe et al., 1985). The consensus criteria are: a history of widespread musculoskeletal pain, and pain in 11 of 18 tender point sites on digital palpation.

Fibromyalgia is the third most common disorder in rheumatologic practice following osteoarthritis and rheumatoid arthritis (RA). In a large study $(\mathrm{N}=1,473)$ of FM in specialty rheumatological clinics, the prevalence of FM was found to be $15.9 \%$ (Wolfe \& Cathey, 1983). FM symptoms are also common, though under-recognized, in primary care with an estimated prevalence of $6 \%$ (Campbell et al., 1983). A study of a community population found an overall prevalence of fibromyalgia of $3.3 \%$ with a $3: 1$ female to male ratio (White et al, 1999). Other community studies report rates of $0.75 \%$ and 2\% (Makela \& Heliovaara, 1991; Wolfe et al, 1995). Mood disturbance is common among FM patients (Clark et al., 1985; Goldenberg, 1986; Wolfe, 1986), but while an association with major depression was found in one study (Hudson et al., 1985), this was not confirmed in others (Ahles et al., 1987; 1991; Kirmayer, Robbins \& Kapusta, 1988). Patients with FM have high levels of physical disability (White et al, 1999b). A study of work disability found that $16 \%$ of FM patients were receiving US Social Security disability payments compared to $2.2 \%$ of the US population (Wolfe et al, 1997). 
Chronic Fatigue Syndrome (CFS)

The U.S. Centers for Disease Control has recommended diagnostic criteria for CFS (Holmes et al., 1988; Fukuda et al, 1994). There are two major criteria: 1) the new onset of debilitating fatigue, persisting or relapsing for at least six months, and 2) no evidence of any other clinical condition that could explain the presence of the fatigue. The minor criteria involve the presence of at least 6 of 11 of the following non-specific constitutional symptoms: mild fever, sore throat, painful cervical or axillary lymph nodes, myalgia, prolonged fatigue after exercise, headache, arthralgias, neuropsychological symptoms (e.g. photophobia, irritability, difficulty thinking, depression), and sleep disturbance.

Fatigue is a very common symptom in community populations. Surveys in Britain and North America find that more than $20 \%$ of adults report feeling "tired all the time" (cf. Wessely, 1989). The prevalence of CFS in studies of primary care patients ranges from 11 to $21 \%$ (Wessely, 1997; Buchwald et al, 1987) while community studies report a prevalence of 0.2 to $0.6 \%$ (Steele et al, 1998; Lawrie \& Pelosi, 1995; Jason et al, 1999). A primary care survey found that $21 \%$ were suffering from symptoms consistent with CFS (Buchwald, Sullivan, Komaroff, 1987). The mean duration of fatigue was 16 months (ranging from 6 to 458 months) and $28 \%$ of patients had been completely bedridden at some time due to the severity of their fatigue. Sixty percent reported that their symptoms had caused considerable stress at work or at home, and many reported symptoms of depression. Several studies report a high prevalence of psychiatric disorders, primarily major depression, anxiety and somatization disorder, among patients with CFS (Hickie et al., 1990; Kruesi, Dale \& Straus, 1989; Manu, Lane \& Matthew, 1989). It remains 
unclear, however, whether the depressive episode occurs after the onset of CFS symptoms and so could be interpreted as a response to chronic illness. CFS is usually described as a chronic disorder with a poor prognosis. Although patients do not seem to suffer from excess medical morbidity they do tend to report persistent work and social disability (Kroenk et al., 1988; Wessely \& Powell, 1989).

\section{STIGMA}

Stigma refers to a persistent trait of an individual or group which evokes negative or punitive responses (Susman, 1994). Stigma is closely related to the notion of "deviance", or negative difference from accepted or valued norms in a social system. Difference from the prevailing norm does not necessarily lead to stigmatization, this occurs when the perception of difference is judged to be a negative distinction. The process of being compared to societal norms, in a subjective fashion, indicates that stigma is not a static phenomenon. Rather, stigma is a social phenomenon subject to fluctuations based on social context and societal change. Furthermore, stigma is not a unidirectional process of the non-stigmatized towards the stigmatized. Current theories of stigma identify the active role the stigmatized individual may have. It is acknowledged that the perception of stigma is influenced by pre-existing self views of the stigmatized (Cioffi, 2000), and that the manifestation of stigma on a dyadic or sociological level may involve the actions of the stigmatized consistent with a self-fulfilling prophesy of stigma (Jussim et al, 2000). This may account for some of the individual variation in the perception of stigma. 
Stigma continues to exist in society in part because it serves various social and psychological functions. On an individual psychological level, stigmatizing others may serve to bolster the individual's self esteem (Wills, 1981), and increase the sense of control over anxiety and threat (Soloman et al, 1991; Dovidio et al, 2000). Other clear benefits to the stigmatizer include preserving an existing social advantage of certain individuals and groups over others (Crocker et al, 1998). A biocultural explanation emphasizes the evolutionary advantages that stigma may have in the containment of nonproductive or actively destructive behaviours in society (Neuberg et al, 2000). Individuals tend to justify maintaining stigma in society with the use of ideologies that rationalize its presence. These include an attributional justification in which individuals are held responsible for their fate (Lerner, 1980), and a hierarchical justification based on social darwinist principles that true differences exist between groups that justify their social status (Crandall, 2000).

Stigma has a variety of negative effects on individuals. Stigmatized individuals report increased social anxiety and behavioural inhibition (DePaulo et al, 1990; Josephs et al, 1992; Schlenker \& Leary, 1982). There is also a tendency for stigmatized individuals to identify with stereotypes and avoid situations in which they may forgo opportunities to prove stereotypes wrong (Pinel, 1999). Although self-esteem may also be negatively affected, it is not universally lower in stigmatized groups, and may even be protective allowing individuals to attribute negative experiences and interactions to a stigmatizing trait rather than personal abilities or characteristics (Crocker \& Quinn, 2000). A concealable stigma can be as distressing as one that is readily apparent. The preoccupation with a stigma and the suppression of related thoughts lead to cognitive 
deficits (Lord \& Saenz, 1985; Gilbert et al, 1988; Lane \& Wegner, 1995) such as impaired concentration, as well as intrusive distressing thoughts (Wegner \& Erber, 1992; Wegner et al, 1993). The attempt to keep a concealable stigma hidden from others, may even have a negative effect on health outcomes (Smart \& Wegner, 2000).

In a seminal publication, "Stigma: Notes on the Management of Spoiled Identity", Goffman (1963) described three types of stigma: "abominations of the body" which refers to physical abnormalities and medical conditions, "blemishes of individual character" which includes behavioural deviance and mental disorders, and "tribal identities", including race and religion. This thesis deals with the first two types, stigma associated with medical conditions and mental disorders.

\section{Stigma of Medical Conditions}

Jones (1984) proposed illness characteristics that lead to or modify stigmatization. These are concealability, severity, disruption to social interactions, aesthetic quality, origin of the condition, and the danger it may pose to others. Historically, the most stigmatized medical conditions have been contagious diseases believed to be associated with immoral or deviant behaviour, and resulting in visible physical deformities. Examples include leprosy (Atta Bainson \& Van den Borne, 1998), syphilis (Whitty, 1999), tuberculosis (Yamada et al, 1999; Kelly, 1999), and in modern times, AIDS. These are good examples of how stigma fluctuates with context and social change. The stigma associated with leprosy, syphilis, and tuberculosis has decreased dramatically with the advent of antimicrobial agents, except in parts of the world where basic health care to treat these conditions is not available. Stigma associated with these conditions has also 
decreased as social views regarding sexual practices have become less judgmental (Gilman, 1999).

AIDS may be the modern day successor of these highly stigmatized conditions (King, 1989; Herek \& Glunt, 1988; Alonzo \& Reynolds, 1995; St Lawrence et al, 1990). It incorporates many of the elements of stigmatizing conditions: fatal outcome, visible Kaposi's sarcomas and wasting, fear of contagion, and the association with homosexual contact which continues to evoke moral judgements. Again with this example, the development of treatments, awareness that HIV is not restricted to the homosexual community and is not transmitted without contact with blood or sexual activity, has likely decreased the stigma of this condition in recent years.

Medical conditions without visible physical deformities can also be very stigmatizing. Epilepsy has the stereotype of unusual physical manifestations of the generalized tonicclonic seizures (Ryan et la, 1980; Ridsdale et al, 1996; Britten et al, 1984). These were historically misunderstood to be evidence of demonic spirit possession and feared as dangerous to others. Until relatively recent technology of electroencephalogram testing which identified epilepsy as a neurological condition, it was commonly believed to be a mental illness and subject to the associated stigma.

Not all stigmatizing physical conditions involve ongoing illness. Congenital limb defects (Frank, 1988), port-wine stains (Lanigan, 1991), acne (Lowe, 1993), burns (Knudson-Cooper, 1981), surgical deformities (Devins, 1994), and hair-loss due to chemotherapy (Reid, 1997) evoke a large degree of stigma without any active illness or risk of danger to others. In these cases, the overriding cause of stigma is the esthetic effect, although restriction of physical function may also be a contributing factor. 
Individuals with serious conditions that are not readily apparent also report feeling stigmatized; examples include cancer (Muzzin et al, 1994), diabetes (Hopper, 1981), and asthma (Snadden, 1992). These individuals are less stigmatized because their illness is concealed. However, the maintenance of secrecy by individuals with these conditions tends to lead to anxiety, depression and may cause cognitive impairments (Smart \& Wegner, 2000).

There is objective research evidence to support the idea that different characteristics of medical conditions evoke various degrees of stigma. A survey of professionals and managers regarding the social distance that they would consider acceptable with individuals described with a wide variety of diagnoses found four factors grouping stigmatized conditions (Albrecht et al, 1982). The least stigmatized included diagnoses that were medically serious but not visible, such as asthma and arthritis. This was followed by conditions that were visible but benign, such as acne, scars, and obesity. Greater degrees of stigma were associated with descriptions of individuals with severe and visible physically disabling conditions such as paraplegia and amputation. The highest level of stigma was associated with a history of criminal behaviour, substance abuse and a diagnosis of a mental illness.

\section{Stigma of Mental Disorders}

The finding in the study by Albrecht and colleagues (1982) that mental disorders are the most stigmatized of medical conditions is consistent with many reports of unfavourable attitudes towards people with mental illness (Byrne, 1997; Link et al, 1997; Jorm et al, 1999). Undertaking psychological therapy is stigmatizing (Sibicky et al, 
1986), and merely consulting a psychiatrist is often avoided due to the fear of social repercussions (Compton \& Stanford, 1976). A recent survey of public opinions concerning mental illnesses in the UK found that individuals with schizophrenia, alcoholism and drug addiction, were perceived to be unpredictable and dangerous (Crisp et al, BJP, 2000). Respondents also believed that drug and alcohol problems were selfgenerated. Other studies have also found high degrees of stigma associated with severe psychiatric conditions and particularly those thought to be behaviourally caused (Weiner et al, 1988; Crandall \& Moriarty, 1995). In the UK survey (Crisp, 2000), individuals with less severe mental illnesses such as depression and anxiety disorders were perceived to be difficult to talk to. The disruption of usual social interactions was also proposed in the study by Albrecht and colleagues (1982) to explain the stigma of mental illness. Other contributing factors included the notion that depression and anxiety reflect a flawed character or moral weakness.

The social and psychological consequences of stigma pervade the lives of individuals with mental illness. It is reported to contribute to low self-esteem, depression (Link et al, 1997; Wahl, 1999), and decreased general life satisfaction (Markowitz, 1989; Rosenfield, 1997). It also affects employment opportunities (Farina et al, 1971), social networks (Link et al, 1989, Wahl, 1999), and extends its negative effects to the families of those with mental illness (Wahl \& Harman 1989).

Stigma of Functional Somatic Syndromes

Although stigma has not been extensively researched in functional somatic syndromes, it has been implicated as a relevant issue from several different perspectives. Individuals 
with FSS share the dilemma of having physical symptoms without a clear medical cause, which often becomes as much a focus of concern as the physical symptoms themselves. In addition to the lack of treatment options for medically unexplained syndromes, patients may feel they are denied the validation of their illness that comes from a medical diagnosis.

The traditional medical model emphasizes a single medical cause leading to well characterized physical effects. This model does not provide for situations in which no medical explanation can be found for the presenting symptoms (Kirmayer, 1994), which leads to the tendency to attribute these symptoms to emotional causes. Studies of chronic facial pain syndrome, or temporomandibular joint pain (TMJP) illustrate this process. The chronic course and lack of acute injury in TMJP does not conform to the more acute pattern of "normal" pain (Kotarba, 1983; Hilbert, 1984). Patients with TMJP report feeling blamed for their problems when behavioural explanations such as teeth grinding are proposed (Marbach et la, 1988; 1990), and given pejorative labels for their condition as psychogenic (Lennon et al, 1989, Feinmann, 1983) or a depressive equivalent (Ford, 1983).

Beliefs regarding the possible causes of FSS are debated within the medical community. Although there is considerable interest in researching biological underpinnings of FSS, there is skepticism regarding the validity of these diagnoses as medical diseases. Recent reviews of this topic (Barsky \& Borus, 1999; Wessely et al, 1999) have emphasized the lack of specific diagnostic criteria, the large degree of overlap between these conditions, and the coexistence of psychiatric conditions including anxiety and depression. This ambiguity has been a source of conflict between the medical 
community and patient advocacy groups who strive to improve the social acceptability of these disorders through their validation as medical conditions.

The desire of individuals with FSS to avoid the label and stigma of having a psychological condition has been proposed as a factor in the development of unexplained medical symptoms and syndromes. When distress is expressed as physical symptoms it may present a more positive image to others than if it were expressed in psychological terms (Paulhus, 1984; Warrenburg et al, 1989). Evidence supporting this theory comes from studies showing greater need for social approval in patients with irritable bowel syndrome (Toner et al, 1992) compared to patients with depression, and higher rates of stigma reported by patients with depression as compared to those presenting with disorders of medically unexplained symptoms (Raguram et al, 1996). 


\section{OBJECTIVES}

The overall objective of this study was to determine whether the status of having a medically unexplained condition contributes to perceived stigma. This was done by comparing levels of perceived stigma among three functional somatic syndromes, (fibromyalgia, chronic fatigue syndrome, and irritable bowel syndrome) and appropriate medical control groups. First, levels of perceived stigma were compared across the six diagnostic groups in the study, to determine if the FSS groups report relatively high rates of stigma. Second, the levels of perceived stigma were compared between each of the three functional somatic syndromes and its medical control group. Third, the effect of having a FSS on perceived stigma was explored by multivariate methods to control for the possible confounding variables of depression and level of physical functioning. The data were drawn from a study designed to validate a structured diagnostic interview for the three functional somatic syndromes: fibromyalgia, chronic fatigue syndrome, and irritable bowel syndrome (Kirmayer, Robbins, Taillefer, Helzer, 1995). 


\section{HYPOTHESES}

1. The three functional somatic syndromes will each have higher levels of perceived stigma than the corresponding comparison medical control groups.

2. When each FSS is aggregated with its corresponding medical comparison group, elevated levels of depression and decreased levels of physical functioning will be positively correlated with perceived stigma.

3. When each FSS is aggregated with its corresponding medical comparison group, having a functional somatic syndrome will be associated with greater perceived stigma when depression and physical functioning are statistically controlled. 


\section{METHODS}

\section{SAMPLE \& PROCEDURES}

Patients were recruited from specialty clinics in a university teaching hospital and affiliated private practice clinics of internists in rheumatology, gastroenterology, immunology, and neurology. Each clinic or practice enrolled consecutive eligible patients with FSS. Patients were eligible if they spoke English or French, and met the standard diagnostic criteria for chronic fatigue syndrome (Fukuda et al, 1994), fibromyalgia (Wolfe et al, 1985), or irritable bowel syndrome (Thompson, 1989), assessed by the referring physician.

Each of the three functional somatic syndromes was compared to a control group of patients with a diagnosis with a clear medical origin drawn from the same clinical settings. The comparison diagnostic groups were selected on the basis of the similarity in symptoms. Thus, fibromyalgia was matched to rheumatoid arthritis due to the common problem of pain. Irritable bowel syndrome was matched to inflammatory bowel disease on the basis of the similarity of bowel symptoms. Chronic fatigue syndrome was matched to multiple sclerosis on the basis that both produce fatigue. The latter is the weakest of the three matches because there can be diverse neurological complications of multiple sclerosis. To maintain the similarity between the groups, multiple sclerosis patients with significant motor deficits were excluded from the study.

Patients from the FSS groups were matched for age and sex to subjects from the selected medical control group, to control for the higher prevalence of depression and 
FSS found in women, and how these conditions vary with age. Research assistants met with subjects at their home or at the clinic of the referring physician to fill out the questionnaires.

Written consent was obtained using a form approved by the institutional research ethics committee. Ethical approval for the study was obtained from the institutional research ethics committee of the Sir Mortimer B. Davis - Jewish General Hospital.

\section{MEASURES}

Scales and questionnaires were administered to assess perceived stigma and factors expected to contribute to perceived stigma, which might confound the results. Based on the review of literature, possible confounders were the level of depression, and physical disability (physical functioning). Other illness characteristics reported to contribute to stigma are less relevant to these diagnoses. The degree of danger an illness presents to others may be a stigmatizing quality but none of these conditions are contagious or are associated with frightening or violent behaviour. The visibility and esthetic aspects of a condition may also lead to stigma, but in the case of these diagnoses there are few visible manifestations of the illness. One exception would be neurological complications of multiple sclerosis producing motor deficits, but these patients were excluded. All measures were self-report questionnaires that were translated into French and checked for semantic equivalence by back-translation.

Sociodemographic Information: A structured interview collected sociodemographic information including age, sex, marital status, and employment status. 
Depression: Depression was measured using 13-items from the depression sub-scale of the Symptom Checklist 90-R, which has good internal consistency, and convergent validity compared with other standard depression scales (Derogatis, 1994). The response scale was modified to an ordinal scale for the number of days in the past month for which the symptom was present. This was done to assess not just the presence of the symptom but its duration as well. Answers were scored as follows: 0 for 0 days, 1 for 1-6 days, 2 for 7-14 days, and 3 for $>14$ days. The total depression score was the sum of the item scores producing the possible range of 0 to 39 . The psychometric properties of this modified scale based on the total sample of 240 subjects in the study include the internal consistency alpha of 0.85 , and a range of item to total correlations of 0.42 to 0.73 , with only two items below 0.5 .

Physical Functioning: Physical functioning was measured using the Physical Composite Score (PCS) of the Medical Outcomes Scale SF-36 (McHorney, Ware \& Raczek, 1993; Ware \& Sherbourne, 1992). This scale consists of 36 items divided into 9 subscales : (1) Physical Functioning, (2) Role Functioning-Physical, (3) Bodily Pain, (4) General Health, (5) Vitality, (6) Social Functioning, (7) Role Functioning-Emotional, (8) Mental Health, and (9) Reported Health transition (a single 4 point item asking the respondent to evaluate how his/her health has changed compared to one year ago). The reliability of these scales range from 0.78 for the General Health scale to 0.93 for the Physical Functioning scale (Ware et al, 1992; McHorney et al, 1993). The PCS scale indicates disability due to illness with a low score, while better functioning due to relatively good health is given a high score. The scales were scored according to procedures developed for the MOS. Accordingly, a scale score was calculated if a respondent answered at least 
half of the items in the multi-item scale, and missing values were replaced with the average score across completed items in the same scale for the individual.

Perceived Stigma: Perceived Stigma was measured by the Attitudes of Others Scale that included 7 items adapted from the Explanatory Model Interview Catalogue (EMIC; Weiss et al, 1992), and 15 items adapted from the Pain-Stigma scale (Lennon et al, 1989). These 22 items were rated on a ordinal scale of $1-4$ based on degree of agreement, and scored as the sum of the individual item responses for a total score range of 22-44. The psychometric properties of this scale based on the total sample of 240 subjects in the study include the internal consistency alpha of 0.91 , and a range of item to total correlations of 0.34 to 0.78 , with only two items below 0.5 . The items formed a single factor on factor analysis (Kirmayer et al, 1995).

\section{DATA ANALYSIS}

Data analysis was performed using SPSS 9.0 software for IBM (1999). Means of total scores for perceived stigma were compared across all diagnostic groups using ANOVA with post-hoc Bonferroni statistics. Differences in sociodemographic data, rates of depression, physical functioning and perceived stigma between each FSS and its respective medical control group were identified using Chi Square and t-test statistics. Bivariate statistics were used to identify correlations between the variables of age, gender, rates of depression, and physical functioning with perceived stigma within the three matched diagnostic groups. Stepwise multiple linear regression statistics were performed for each of the three matched diagnostic groups, to determine if the FSS 
diagnosis made an independent contribution to perceived stigma, when depression and physical functioning were also included as independent variables. An alpha of 0.05 was used for tests of significance. 


\section{RESULTS}

\section{CHARACTERISTICS OF THE SAMPLE}

A total of 265 subjects were enrolled in the study: 41 fibromyalgia (FM), 43 rheumatoid arthritis (RA), 41 irritable bowel syndrome (IBS), 55 inflammatory bowel disease (IBD), 45 chronic fatigue syndrome (CFS) and 40 multiple sclerosis (MS). 68 (26\%) of subjects were French speaking, and 197 (74\%) were English speaking. Patients were accrued from a total of 18 physicians at 16 different sites. In general, the FSS group and the non-FSS comparison group came from similar settings. The exceptions were CFS and MS: all of the MS patients were referred from hospital based neurology practices while the CFS were referred by both hospital and private office-based clinicians with specific interest in this problem, including general internists, infectious disease specialists, immunologists, and psychiatrists. In the cases of CFS referred to the study by a psychiatrist, the diagnosis had been previously ascertained by a medical specialist.

Patients in the FSS groups were consecutive patients recruited from their respective clinics and practices. Samples of patients with the corresponding medical disorders may be less representative of their respective clinic populations because they were chosen to match the FSS patients on age and gender. The matching procedure was successful in that there were no significant differences between FSS patients and corresponding medical disease patients on age and gender. 


\section{PERCEIVED STIGMA}

The rates of perceived stigma were different across the six diagnostic groups $(F(5)=16.537, p<0.001$ ) (Figure 1). Posthoc Tukey tests found that perceived stigma in the CFS group was higher than any other group $(\mathrm{p}<0.01)$, and perceived stigma in the MS group was higher than in the RA $(\mathrm{p}<0.05)$ and IBS $(\mathrm{p}<0.01)$ groups. There were no statistical differences in perceived stigma between FM, RA, IBS, and IBD. Subsequent analyses were carried out on the matched pairs of diagnostic groups.

Irritable Bowel Syndrome and Inflammatory Bowel Disease:

There were no differences in age, sex, rates of depression or physical functioning, between the IBS and IBD groups (Table 1). Of these variables, only depression $(r=0.32$, $\mathrm{p}<0.01)$, and physical functioning $(\mathrm{r}=-0.26, \mathrm{p}<0.05)$ scores were correlated with perceived stigma on bivariate analysis. In the stepwise multiple linear regression model (Table 2) (adjusted $\left.R^{2}=0.14, F(2,78)=7.53 p<0.01\right)$ both depression $(\beta=0.44, t=3.0$, $\mathrm{p}<0.001)$ and physical functioning $(\beta=-0.24, \mathrm{t}=-2.1, \mathrm{p}<0.05)$ remained significant correlates of perceived stigma. Age, gender, and a dummy variable distinguishing between the two diagnostic groups were not significant in the model.

Fibromyalgia and Rheumatoid Arthritis:

Depression was higher in the FM group than the RA group, and there was a trend of higher perceived stigma in the FM group, which did not reach statistical significance (Table 3). Age, sex, and physical functioning scores did not differ between the groups. Of 
these variables, rates of depression $(r=0.49 . \mathrm{p}<0.001)$ and physical functioning $(\mathrm{r}=-0.38$, $\mathrm{p}<0.01)$ were correlated with perceived stigma on bivariate analysis. In the stepwise multiple linear regression model (Table 4) (adjusted $\mathrm{R}^{2}=0.31, \mathrm{~F}(2,69)=17.1, \mathrm{p}<0.001$ ) both depression $(\beta=0.73, \mathrm{t}=4.4, \mathrm{p}<0.001)$ and physical functioning $(\beta=-0.38, \mathrm{t}=-3.1$, $\mathrm{p}<0.01)$ remained significant correlates of perceived stigma. Age, gender, and the dummy variable distinguishing between the two diagnostic groups was not significant in the model.

Chronic Fatigue Syndrome and Multiple Sclerosis:

Stigma was higher in the CFS than in the MS group (Table 5). Although there was a trend for the physical functioning to be lower in the CFS group, this did not reach statistical significance, and there were no other differences between these groups. Bivariate statistics found that physical functioning $(r=-0.26, \mathrm{p}<0.05)$ and depression $(\mathrm{r}=0.32, \mathrm{p}<0.01)$ were correlated with perceived stigma. The stepwise multiple linear regression model (Table 6) (adjusted $\mathrm{R}^{2}=0.34, \mathrm{~F}(2,71)=18.1, \mathrm{p}<0.001$ ) found depression $(\beta=0.68, t=4.2, p<0.001)$ and the dummy variable for $\mathrm{CFS}(\beta=8.5, \mathrm{t}=4.1, \mathrm{p}<0.001)$ to be correlated with perceived stigma. Age, gender, and physical functioning were not significant in the model. 


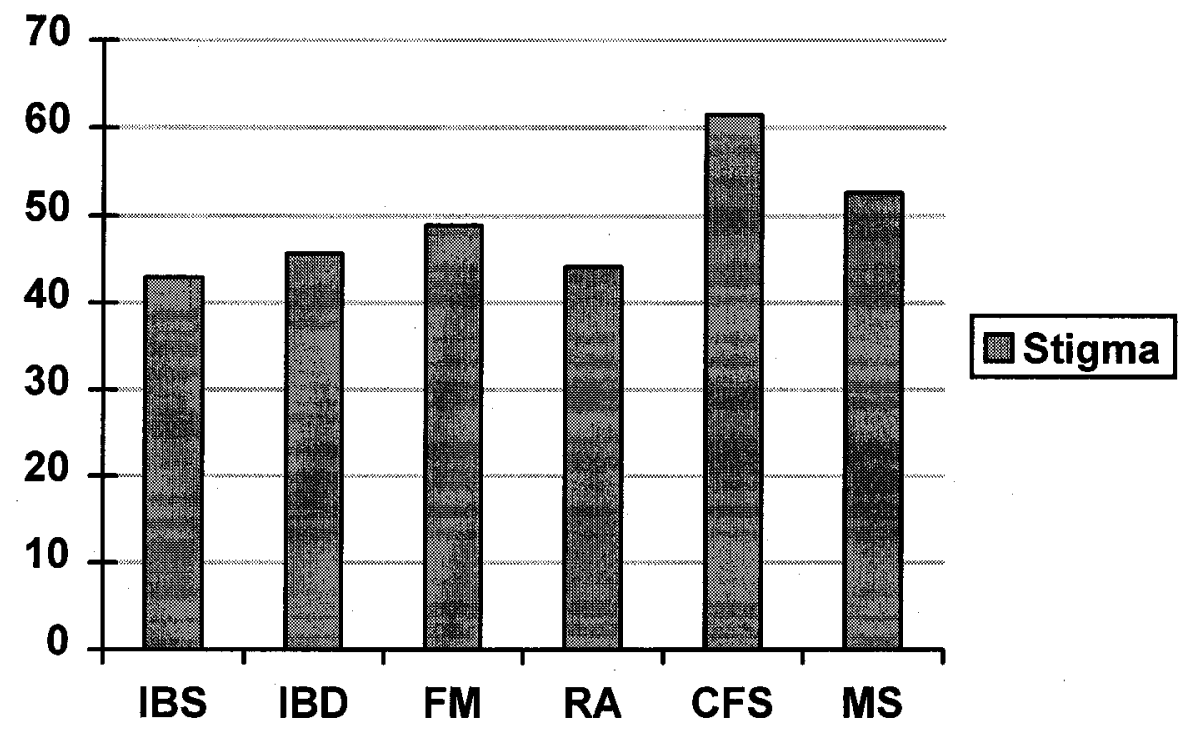

Figure 1:Stigma by diagnostic group: CFS $>$ all groups $(p<0.01)$, MS $>$ RA\&IBS $(p<0.05)$ 
Table 1: Descriptive data for irritable bowel syndrome (IBS) and inflammatory bowel disease (IBD).

\begin{tabular}{lcll}
\hline Variables & IBS (n=41) & IBD (n=55) & Test statistic \\
\hline Sex, n (\%) female & $30(73.2)$ & $36(65.5)$ & $\chi^{2}(1)=0.65, \mathrm{~ns}$ \\
& & & \\
& Mean, SD & Mean, SD & \\
Age & $34.8(11.02)$ & $34.8(12.81)$ & $\mathrm{t}(94)=0.01, \mathrm{~ns}$ \\
$\begin{array}{l}\text { SCL-90-R depression } \\
\text { Physical composite }\end{array}$ & $8.3(7.3)$ & $8.3(7.5)$ & $\mathrm{t}(94)=0.01, \mathrm{~ns}$ \\
score & $47.7(8,6)$ & $45.5(11.7)$ & $\mathrm{t}(85)=1.01, \mathrm{~ns}$ \\
Perceived stigma & $42.9(10.4)$ & $45.7(10.9)$ & $\mathrm{t}(87)=-1.2, \mathrm{~ns}$ \\
\hline
\end{tabular}

Table 2: Stepwise multiple linear regression, for the IBS and IBD group, with perceived stigma as the dependent variable. Adjusted $\mathrm{R}^{2}=0.14, \mathrm{~F}(2,78)=7.53, \mathrm{p}<0.01$

Independent variables $\quad \beta \quad$ SE $(\beta) \quad$ Significance test, $t(p)$

Predictors

$\begin{array}{lrrr}\text { SCL-90-R depression } & 0.44 & 0.15 & 3.00(<0.01) \\ \text { Physical composite score } & -0.24 & 0.11 & -2.11(<0.05)\end{array}$

Excluded Variables

$\begin{array}{lccc}\text { Age } & 0.02 & & 0.17(\mathrm{~ns}) \\ \text { Gender } & -0.15 & & -1.40(\mathrm{~ns}) \\ \text { FSS (IBS: 1=yes, 0=no) } & -0.12 & & -1.19(\mathrm{~ns}) \\ & & & \\ \text { Constant } & 40.15 & 1.71 & 23.5(<0.001)\end{array}$

$\beta$ denotes the unstandardized coefficent 
Table 3: Descriptive data for fibromyalgia (FM) and rheumatoid arthritis (RA).

\begin{tabular}{llll}
\hline Variables & FM (n=41) & RA $(\mathrm{n}=43)$ & Test statistic \\
\hline Sex, n (\%) female & $38(92.7)$ & $37(86.0)$ & $\chi^{2}(1)=0.97, \mathrm{~ns}$ \\
& & & \\
& Mean, SD & Mean, SD & \\
& & & \\
$\begin{array}{l}\text { Age } \\
\text { SCL-90-R depression }\end{array}$ & $13.4(11.6)$ & $52.7(13.6)$ & $\mathrm{t}(82)=-1.4, \mathrm{~ns}$ \\
$\begin{array}{l}\text { Physical composite } \\
\text { score }\end{array}$ & $32.4(11.8)$ & $35.6(6.6)$ & $\mathrm{t}(82)=2.84, \mathrm{p}<0.01$ \\
Perceived stigma & $48.9(13.0)$ & $44.2(11.4)$ & $\mathrm{t}(72)=1.35, \mathrm{~ns}$ \\
& & & $\mathrm{p}=0.096$ \\
\hline
\end{tabular}

Table 4: Stepwise multiple linear regression, for the FM and RA group, with perceived stigma as the dependent variable. Adjusted $\mathrm{R}^{2}=0.31, \mathrm{~F}(2,69)=21.22, \mathrm{p}<0.001$

\begin{tabular}{lrll}
\hline Independent variables & $\beta$ & SE $(\beta)$ & Significance test, $\mathrm{t}(\mathrm{p})$ \\
\hline & & & \\
Predictors & & & \\
SCL-90-R depression & 0.73 & 0.17 & $4.43(<0.001)$ \\
Physical composite score & -0.38 & 0.12 & $-3.19(<0.01)$ \\
Excluded Variables & & & \\
Age & -0.23 & & $-0.23(\mathrm{~ns})$ \\
Gender & -0.10 & & $-0.99(\mathrm{~ns})$ \\
FSS (FM: 1=yes, 0=no) & 0.03 & & $0.31(\mathrm{~ns})$ \\
Constant & 37.4 & 2.32 & $16.1(<0.001)$ \\
\end{tabular}

$\beta$ denotes the unstandardized coefficent 
Table 5: Descriptive data for chronic fatigue syndrome (CFS) and multiple sclerosis (MS).

\begin{tabular}{llll}
\hline Variables & CFS (n=45) & MS (n=40) & Test statistic \\
\hline Sex, n (\%) female & $28(62.2)$ & $30(75.0)$ & $\chi^{2}(1)=1.60, \mathrm{~ns}$ \\
& Mean, SD & Mean, SD & \\
& & & \\
Age & $39.4(9.3)$ & $43.0(11.33)$ & $\mathrm{t}(83)=-1.63, \mathrm{~ns}$ \\
$\begin{array}{l}\text { SCL-90-R depression } \\
\text { Physical composite }\end{array}$ & $12.5(6.5)$ & $11.4(6.8)$ & $\mathrm{t}(83)=0.72, \mathrm{~ns}$ \\
$\begin{array}{l}\text { score } \\
\text { Perceived stigma }\end{array}$ & $61.5(9.2)$ & $34.4(12.9)$ & $\mathrm{t}(80)=-1.75$, \\
& & $52.6(8.1)$ & $\begin{array}{l}\mathrm{t}=0.084 \\
\mathrm{t}(73)=3.91, \mathrm{p}<0.001\end{array}$ \\
\hline
\end{tabular}

Table 6: Stepwise multiple linear regression, for the CFS and MS group, with perceived stigma as the dependent variable. Adjusted $\mathrm{R}^{2}=0.32, \mathrm{~F}(2,71)=18.05, \mathrm{p}<0.001$

\begin{tabular}{lccc}
\hline Independent variables & $\beta$ & SE $(\beta)$ & Significance test, $t(p)$ \\
\hline Predictors & & & \\
SCL-90 depression & 0.67 & 0.16 & $4.16(<0.001)$ \\
FSS (CFS: 1=yes, 0=no) & 8.53 & 2.08 & $4.11(<0.001)$ \\
Excluded Variables & & & \\
Age & -0.01 & & $-0.91(\mathrm{~ns})$ \\
Gender & -0.12 & & $-1.20(\mathrm{~ns})$ \\
Physical composite score & 0.14 & & $1.30(\mathrm{~ns})$ \\
& & & $19.7(<0.001)$ \\
Constant & 48.8 & 2.48 & \\
\hline B denotes the unstandardized coefficent & & \\
\end{tabular}




\section{DISCUSSION}

The first hypothesis of this study was that the FSS would report higher levels of perceived stigma than the medical control groups. This was found only for the CFS group, and not in the IBS or FM groups. In the comparison of perceived stigma across all groups, the CFS group reported a higher level of stigma than any other group, and subjects in the MS group reported higher levels than two other groups. No other differences were detected between the groups. In addition to having the highest rate of perceived stigma on the overall comparison between all groups, the CFS also had reported higher levels of perceived stigma when compared to its medical control groups. This was not seen in the IBS or FM groups.

The second hypothesis was that elevated depression and lower physical functioning would be associated with perceived stigma. This hypothesis was confirmed for most groups. Depression was associated with perceived stigma in all analyses, while physical functioning was associated with perceived stigma in the combined IBS/IBD group and the FM/RA group, but not the CFS/MS group.

The third hypothesis was that when each FSS was aggregated with its medical control group, having a FSS would be independently associated with perceived stigma when controlling for rates of depression and physical functioning in regression analyses. This was observed for CFS but not the other two FSS.

The relatively high rates of perceived stigma in the CFS and the MS groups may be explained by the nature of the symptom of fatigue. Compared to other physical symptoms such as pain in FM and RA or bowel symptoms in IBS and IBD, fatigue is a universal 
and daily phenomenon, may not be as readily associated with being medically ill, and accordingly may elicit less empathy. Furthermore, the behavioural effects of fatigue such as reduced physical and social activity, and the facial appearance of fatigue may cause others to believe the individual is depressed. This may explain higher levels of perceived stigma given the literature indicating increased stigma associated with mental illness (Crisp, 2000; Albrecht et al, 1982). Although individuals with a diagnosis of MS have a clear medical cause for their illness, they often go through a prolonged undiagnosed period early in the evolution of their illness during which they may experience similar frustrations as those with unexplained medical conditions (Duval, 1984).

Having a medically unexplained syndrome contributed to perceived stigma in CFS compared to MS. The additional stigma conferred by having the medically unexplained syndrome is not accounted for by depression or level of physical functioning, as these were controlled for in multivariate analysis. The most likely source of stigma in CFS is the ambiguity regarding the cause of the condition. CFS has been a controversial diagnosis since it became commonly known in the 1980s (Abbey \& Garfinkel, 1991b). Early theories implicated the Epstein Barr Virus as a possible etiological agent (Tobi et al, 1982; Straus et al, 1985) due to the similarity in clinical presentation of the illness, but subsequent research did not support this as a cause of the disorder (Buchwald et al, 1987; Gold 1990). In the absence of the expected traditional characteristics for a medical diagnosis, the validity of CFS as a diagnostic entity has been questioned (Lane et al, 1991). Furthermore, some authors have cautioned against the construction of medical labels to describe symptoms that historically reflect social rather than biological disruption (Shorter, 1992), which is consistent with the observation that physical 
symptoms are the most common manifestation of social and emotional distress (Kirmayer \& Young, 1998). Individuals with CFS have felt discredited by such opinions and indeed have been subjected to pejorative labels (Brickman and Fins, 1993) such as the "Yuppie flu" (Cooke, 1991), which is based on the early stereotype of CFS affecting people in higher socioeconomic classes. Others have questioned the possibility that CFS may be a manifestation of depression (Abbey \& Garfinkel, 1991; 1991b). The very issue of providing a diagnosis that is acceptable to the afflicted individual gives rise to controversy (Brown, 1995). While some report that having a diagnosis helps individuals cope with feeling unwell (Woodward, 1993), other evidence suggests that reinforcing the notion that medically unexplained symptoms are biological in origin may be implicated in the chronicity of the disorder (Butler et al, 1991).

Medically unexplained syndromes may be classified as psychosomatic, which is a category of illness intended to breech the gap between the mind-body dualism in western medicine, to encompass illnesses that can not be clearly categorized as medical or psychological. However, this label has taken on a negative image and is commonly interpreted as an equivalent of psychiatric or psychological disorder (Willis, 1994). The struggle for legitimation in CFS has remained focussed largely on achieving recognition of the disorder as a medical condition, and obtaining the benefits of a disabling medical illness (Beaulieu, 1997). Meanwhile, attempts to understand medically unexplained syndromes in a socio-culturally sensitive way (Kirmayer, 1999) are lost in conflicts of social and medical politics.

Having a medically unexplained syndrome did not contribute to perceived stigma in the model found for the IBS and IBD group. The absence of an effect of this variable as a 
predictor of perceived stigma may indicate different attitudes towards IBS. In the case of the IBS and IBD group, the medically unexplained nature of IBS likely does not become an issue. The general public may not be aware of the distinction between the two diagnoses. Within the medical community, IBS patients tend to be followed by gastroenterolgists and are less frequently referred to mental health professionals due to an assumption that the symptoms are related to emotional issues.

Having a medically unexplained syndrome also did not contribute to perceived stigma in the model found for the FM and RA group. The trend for the medically unexplained syndrome to be associated with perceived stigma on bivariate but not multivariate analysis indicates the possibility that the sample lacked the statistical power to detect a significant effect. As a social phenomenon, stigma shifts with sociological change. Fibromyalgia has been known as a physical problem for a longer period than CFS, over time it has gained in acceptance within the medical community as a pain disorder and has become more familiar as a valid health problem in the media and general public (Kirmayer, 1999). Although the medically unexplained status remains an issue for patients with FM but it may not lead to the same degree of stigma that is reported by patients with CFS. 


\section{LIMITATIONS}

This study deals with the patient's own perception of stigma and did not include objective markers such as reports of discrimination, or surveys of the public or health care professionals. The lack of objective markers limits our ability to describe the severity of perceived stigma and its impact on daily life. Few studies have used objective measures to demonstrate negative views towards individuals with CFS. However, numerous authors describe the negative attitudes towards various medically unexplained syndromes (Beaulieu, 1997; Kirmayer, 1999; Hall \& Morrow, 1988; Bammer, \& Martin, 1992; Lennon et al, 1989), and account for these primarily by the attributions of symptoms to psychiatric and psychological illness which have been shown to be highly stigmatized (Crisp et al, 2000; Markowitz 1998; Albrecht et al, 1982). Even in the absence of objective evidence of stigma, there is some evidence that the perception of stigma can lead to significant emotional distress (Scambler, 1984; Scambler \& Hopkins, 1990). Subjective reports of stigma may have been influenced by the mood states and attitudes of respondents. This was partially controlled for by including a measure of depression in the multivariate analysis, however, personality traits such as negative affectivity, which is the tendency to experience events in a negative way, remain as possible confounding variables.

Causes of stigma not measured in this study include the effect of the visible effects of the disease. Although multiple sclerosis produces severe visible effects in the advanced stages of the illness, these patients were excluded from the study. The remaining conditions in this study are not associated with remarkable physical deformity, but subtle 
unmeasured changes may have an effect. For example, a change in gait due to pain, or the facial appearance of pain or fatigue.

Another limitation of the study is the cross-sectional design which does not allow the direction of causality between predictive variables and the outcome to be established. Thus, the degree to which depression and physical functioning lead to perceived stigma as opposed to the reverse or some combination thereof is not known.

Future studies can clarify these issues using a longitudinal study design, both subjective and objective measures of stigma, and enrolling subjects from patient groups, health care professionals, and the general public. The relationship between psychological symptoms, physical symptoms, and stigma could also be investigated with the use of a longitudinal design. Of particular interest would be to repeat surveys over the course of several years or different geographical regions to identify how attitudes towards different medically unexplained syndromes change, and to relate this change to medical, social and cultural developments. 


\section{CONCLUSION}

Three functional somatic syndromes were compared to medical control groups to determine whether having a condition of medically unexplained origin contributes to perceived stigma. The results indicate that this may be true for the chronic fatigue syndrome group, where having the medically unexplained syndrome was a predictor of perceived stigma even when controlling for the degree of depression and physical functioning in multivariate analysis. This association was not seen in the fibromyalgia or irritable bowel syndrome groups, which may reflect a greater acceptance of these syndromes as medical conditions. The relationship between perceived stigma and objectively measured stigma, how these phenomena fluctuate with social change, and their effect on health care use and work disability are topics for further research. 


\section{ACKNOWLEDGMENTS}

I would like to thank Dr. Laurence Kirmayer and his research associates on the Functional Somatic Syndromes study, Suzanne Taillefer, and James Robbins, for allowing me to use the data from their study for my thesis. The Functional Somatic Syndromes study was funded by a grant from the Fonds de la recherche en santé du Québec. I would also like to thank Dr. Laurence Kirmayer and Dr. Guillaume Galbaud du Fort for their support and scientific contributions at every step of this work from the planning to data analysis and manuscript preparation. 


\section{REFERENCES}

Abbey, SE, \& Garfinkel, PE. (1991). Chronic fatigue syndrome and depression: cause effect or covariate. Review of Infectious Diseases 13 (Suppl. 1): s73-83.

Abbey, S, \& Garfinkel, PE. (1991b). Neurasthenia and chronic fatigue syndrome: the role of culture in the making of a diagnosis. American Journal of Psychiatry, 148, 16381646.

Ahles, T. A., Khna, S. A., Yunus, M. B., Spiegel, D. A., \& Masi, A. T. (1991).

Psychiatric status of patients with primary fibromyalgia, patients with rheumatoid arthritis, and subjects without pain: A blind comparison of DSM-III diagnoses. American Journal of Psychiatry, 148, 1721-1726.

Ahles, T. A., Yunus, M. B., \& Masi, A. T. (1987). Is chronic pain a variant of depressive disease? The case of primary fibromyalgia syndrome. Pain, 29, 105-111.

Albrecht, G. L., Walker, V. G., \& Levy, H. A. (1982). Social distance from the stigmatized: A test of two theories. Social Science and Medicine, 16, 1319-1327.

Alonzo, A. A., \& Reynolds, N. R. (1995). Stigma, HIV and AIDS: an exploration and elaboration of a stigma trajectory. Social Science \& Medicine, 41, 303-15.

Atta Bainson, K., \& Van Den Borne, B. (1998). Dimensions and process of stigmatization in leprosy. Legr Rev, 69, 341-350.

Barsky, A. J., \& Borus, J. F. (1999). Functional Somatic Syndromes. Annals of Internal Medicine, 130, 910-921.

Beaulieu, M. (1997). Sigma and legitimation in chronic fatigue syndrome: the role of social location. Department of Sociology, McGill University, Ph.D. Dissertation. 
Bennett, R. M. (1987). Fibromyalgia. Journal of the American Medical Association, $257(20), 2802-2803$.

Brickman, A. L., \& Fins, A. I. (1993). Psychological and cognitive aspects of chronic fatigue syndrome. In Paul J. Goodnick and Nancy G. Klimas (Eds.) Chronic Fatigue and Related Immune Deficiency Syndrome. Washington D.C.: American Psychiatric Press Inc.

Britten, N., Wadsworth, M. E., \& Fenwick, P. B. (1984). Sigma in patients with early epilepsy: a national longitudinal study. Journal of Epidemiology \& Community Health, $38,291-5$.

Brown, P. (1995). Naming and framing: the social construction of diagnosis and illness. Journal of Health and Social Behavior. Extra Issue, 34-52.

Buchwald, D., Sullivan, J. L., \& Komaroff, A. L. (1987). Frequency of "Chronic Active Epstein-Barr Virus Infection" in a general medical practice. JAMA, 257(17), 23032307.

Butler, S., Chalder, T., Ron, M., \& Wessely, S. (1991). Cognitive behaviour therapy in chronic fatigue syndrome. Journal of Neurology, Neurosurgery, and Psychiatry, 54, $153-158$.

Byrne, P. (1997). Psychiatric stigma: past, passing and to come. Journal of the Royal Society of Medicine, 90, 618-621.

Campbell, S. M., Clark, S., Tindall, E. A., Forehand, M. E., \& Bennett. (1983). Clinical characteristics of fibrositis: I. A blinded, controlled study of symptoms and tender points. Arthritis and Rheumatism, 26(7), 817-824. 
Cioffi, D. (2000). The looking-glass self revisited: behavior choice and self-perception in the social token. In T. F. Heatherton, R. E. Kleck, M. R. Hebl, \& J. G. Hull (Eds.), The Social Psychology of Stigma. New York, NY: The Guilford Press.

Clark, S., Campbell, S.M., Forehand, M. E., Tindall, E. A., \& Bennett, R. M. (1985). Clinical characteristics of fibrositis: II. A "blinded," controlled study using standard psychological tests. Arthritis and Rheumatism, 28(2), 132-137.

Compton, J., \& Stanford, F. (1976). The stigma of seeing a psychiatrist. American Journal of Psychotherapy, 30, 473-82.

Cooke, R. G. (1991). The psychiatrist and chronic fatigue syndrome. Proceedings of a Workshop of Chronic Fatigue Syndrome. Toronto, Ontario: 28-29 September 1989: Canada Diseases Weekly Report. Volume 17S1E.

Crandall, C. S. (2000). Ideology and lay theories of stigma: the justification of stigmatization. In T. F. Heatherton, R. E. Kleck, M. R. Hebl, \& J. G. Hull (Eds.), The Social Psychology of Stigma. New York, NY: The Guilford Press.

Crandall, C. S., \& Moriarty, D. (1995). Physical illness stigma and social rejection. British Journal of Psychology, 34, 67-83.

Crisp, A. H., Gelder, M. G., Rix, S., Meltzer, H. I., \& Rowlands, O. J. (2000). Stigmatisation of people with mental illnesses. British Journal of Psychiatry, Crocker, J., Major, B., \& Steele, C. (1998). Social stigma. In D. T. Gilbert, S. T. Fiske, \& G. Lindzey (Eds.), Handbook of social psychology ( $4^{\text {th }}$ ed., Vol. 2, pp. 504-553). Boston: McGraw-Hill. 
Crocker, J. \& Quinn, D. M. (2000). Social stigma and the self: meanings, situations, and self-esteem. In T. F. Heatherton, R. E. Kleck, M. R. Hebl, \& J. G. Hull (Eds.), The Social Psychology of Stigma. New York, NY: The Guilford Press.

DePaulo, B. M., Epstein, J. A., \& Lemay, C. S. (1990). Responses of the socially anxious to the prospect of interpersonal evaluation. Journal of Personality, 58, 623-640.

Derogatis, L. R. (1994). SCL-90-R, Brief Symptoms Inventory, and matching clinical rating scales. In M. Maruish (Ed.), Psychological Testing, Treatment Planning and Outcome Assessment. New York: Erlbaum.

Devins, G. M., Henderikus, J. S., \& Koopmans, J. P. (1994). Psychosocial impact of laryngectomy mediated by perceived stigma and illness intrusiveness. Canadian Journal of Psychiatry, 39, 608-616.

Dovidio, J. F., \& Gaertner, S. L. (1998). On the nature of contemporary prejudice: The causes, consequences, and challenges of aversive racism. In J. Eberhardt \& S. T. Fiske (Eds.), Confronting Racism: The Problem and the Response (pp. 3-32). Thousand Oaks, CA: Sage.

Drossman, D. A., McKee, D. C., Sandler, R. S., Mitchell, C. M., Cramer, E. M., Lowman, B. C., \& Burger, A. L. (1988). Psychosocial factors in the irritable bowel syndrome: A multivariate study of patients and nonpatients with IBS. Gastroenterology, 95, 701-708.

Drossman, D. A., Sandler, R. S., McKee, D. C., \& Lovitz, A. J. (1982). Bowel patterns among subjects not seeking health care: Use of a questionnaire to identify a population with bowel dysfunction. Gastroenterology, 83, 529-534. 
Drossman, D. A., Powell, D. W., \& Sessions, J. T., Jr. (1977). The irritable bowel syndrome. Gastroenterology, 73, 811-822.

Duval, M. L. (1984) Psychosocial metaphors of physical distress among MS patients. Social Science and Medicine, 19, 635-638.

Farina, A., Gliha, D., Boudreau, L. A., Allen, J. C., \& Sherman, M. Mental illness and the impact of believing others know about it. Journal of Abnormal Psychology, 77, 1-5.

Feinmann, C. (1983). Psychogenic facial pain: Presentation and treatment. Journal of Psychosomatic research, 27, 403-410.

Ford, C. (1983). The Somatizing Disorders: Illness as a Way of Life. New York: Elsevier.

Frank, G. (1988). Beyond stigma: visibility and self-empowerment of persons with congenital limb deficiencies. Journal of Social Issues, 44, 95-115.

Fukuda, K., Straus, S., Hickie, I., Sharpe, M., Dobbins, J. G., Komaroff, A., \& International Chronic Fatigue Syndrome Study Group. (1994). The chronic fatigue syndrome: A comprehensive approach to its definition and study. Annals of Internal Medicine, 121, 953-959.

Gilman, S. L. (2000). Disease and stigma. The Lancet, 354 (SIV), 15-16.

Gilbert, D. T., Krull, D. S., \& Pelham, B. W. (1988). Of thoughts unspoken: Social inference and the self-regulation of behavior. Journal of Personality and Social Psychology, 55, 685-694.

Goffman, E. (1963). Stigma: Notes on the Management of a Spoiled Identity. Englewood Cliffs, N.J.: Prentice-Hall. 
Gold, D., Bowden, R., Sixbey, J., Riggs, R, Katon, W. J., Ashley, R., Obridgewitch, R. \& Corey, L, (1990) Chronic fatigue syndrome. A prospective clinical and virologic study. JAMA, 264, 48-53.

Goldenberg, D. L. (1986). Psychologic studies in fibrositis. American Journal of Medicine, 81(suppl 3A), 67-72.

Hahn, B. A., Yan, S., \& Strassels, S. (1999). Impact of irritable bowel syndrome on quality of life and resource use in the United States and United Kingdom. Digestion, $60,77-81$.

Harvey, F. R. D., Salih, S., \& Read, A. E. (1983). Organic and functional disorders in 2000 gastroenterology outpatients. Lancet, i, 632-634.

Heaton, K. W., O’Donnell, L. J., Braddon, F. E., Mountford, R. A., Hughes, A. O., \& Cripps, R. J. (1992). Symptoms of irritable bowel syndrome in a British urban community: consulters and nonconsulters. Gastroenterology, 102, 1962-7.

Herek, G. M., \& Glunt, E. K. (1988). An epidemic of stigma. Public reactions to AIDS. American Psychologist, 43, 886-91.

Hickie, I., Lloyd, A., Wakefield, D., \& Parker, G. (1990). The psychiatric status of patients with the chronic fatigue syndrome. British Journal of Psychiatry, 156, 534-540.

Hilbert, R. A. (1984). The accultural dimensions of chronic pain: Flawed reality construction and the problem of meaning. Social Problems, 31, 365-378.

Hislop, I. G. (1971). Psychological significance of the irritable colon syndrome. Gut, 12, $452-457$. 
Holmes, G. P., Kaplan, J. E., Gantz, N. M., Komaroff, A. L., Schonberger, L. B.,et al. (1988). Chronic fatigue syndrome: A working definition. Annals of Internal Medicine, $108,387-389$.

Hopper, S. (1981). Diabetes as a stigmatized condition: the case of low-income clinic patients in the United States. Social Science \& Medicine, 158, 11-19.

Hudson, J. L., Hudson, M. S., Pliner, L. F., Goldenberg, D. L., \& Pope, H. G., Jr. (1985). Fibromyalgia and major affective disorder: A controlled phenomenology and family history study. American Journal of Psychiatry, 142(4), 441-446.

Jason, L. A., Richman, J. A., Rademaker, A. W. Jordan, K. M., Plioplys, A. V., Taylor, R. R., McCready, W., Huang, C. F., \& Plioplys, S. (1999). A community-based study of chronic fatigue syndrome. Archives of Internal Medicine, 159, 2129-37.

Jones, E. E., Farina, A., Hastorf, A. H., Markus, H., Miller, D. T., \& Scott, R. A. (1984). Social Stigma: The psychology of marked relationships. New York: Freeman.

Jones, R., \& Lydeard, S. (1992). Irritable bowel syndrome in the general population. British Medical Journal, 304, 87-90.

Jorm, A. F., Jacomb, P. A., Christensen, H., et al (1999). Attitudes towards people with a mental disorder: a survey of the Australian public and health professionals. Australian and New Zealand Journal of Psychiatry, 33, 77-83.

Josephs, R. A., Larrick, R. P., Steele, C. M., \& Nisbett, R. E. (1992). Protecting the self from the negative consequences of risky decisions. Journal of Personality and Social Psychology, 62, 26-37. 
Jussim, L, Palumbo, P., Chatman, C., Madon, S., \& Smith A. (2000). Stigma and selffulfilling prophecies. In T. F. Heatherton, R. E. Kleck, M. R. Hebl, \& J. G. Hull (Eds.), The Social Psychology of Stigma. New York, NY: The Guilford Press.

Katon, W. J., \& Walker, E. A. (1998). Medically Unexplained Symptoms in Primary Care. Journal of Clinical Psychiatry, 59 (suppl. 20), 15-21.

Kelly, P. (1999). Isolation and stigma: the experience of patients with active tuberculosis. Journal of Community Health Nursing, 16, 233-41.

King, M. B. (1989). AIDS on the death certificate: the final stigma. BMJ, 298, 734-6.

Kirmayer, L. J. (1994). Improvisation and authority in illness meaning. Culture and Medical Psychiatry, 18, 183-214.

Kirmayer, L. J. (1999). Rhetorics of the body: Medically unexplained Symptoms in sociocultural perspective. In One, Y. Janca, A. Asai, M. \& Sartorius, N. (Eds.) Somatoform Disorders - A Worldwide Perspective. Keio University Symposia for Life Science and Medicine. Tokyo: Springer-Verlag.

Kirmayer, L. J., Looper, K. J., \& Taillefer, S. (in press). Somatoform Disorders. In M. Hersen \& S. Turner (Eds.) Adult Psychopathology (4 ${ }^{\text {th }}$ Edition), New York: John Wiley.

Kirmayer, L. J., Robbins, J. M., \& Kapusta, M. A. (1988). Somatization and depression in fibromyalgia syndrome. American Journal of Psychiatry, 145(8), 950-954.

Kirmayer, L. J., Robbins, J. M., Taillefer, S. S., \& Helzer, J. E. (1995). Development and validation of a structured diagnostic interview for functional somatic syndromes. Culture \& Mental Health Research Unit. Sir Mortimer B. Davis - Jewish General Hospital, Montreal. Report No. 5. 
Kirmayer, L. J., \& Young, (1998). Culture and somatization: clinical, epidemiological and ethnographic perspectives. Psychosomatic Medicine, 60, 420-430.

Knudson-Cooper, M. S. (1981). Adjustment to visible stigma: the case of the severely burned. Social Science \& Medicine - Medical Anthropology, 15B, 31-44.

Kotarba, J. A. (1983). Chronic Pain: Its Social Dimensions, Beverly Hills, California: Sage.

Kroenke, K., Spitzer, R. L., deGruy, F. V., Hahn, S. R., Linzer, M. Williams, J. B., Brody, D., \& Davies, M. (1997). Multisomatoform disorder. An alternative to undifferentiated somatoform disorder for the somatizing patient in primary care. Archives of General Psychiatry, 54, 352-358.

Kroenke, K., Wood, D., Mangelsdorff, D., et al. (1988). Chronic fatigue in primary care: Prevalence, patient characteristics and outcome. JAMA, 260, 929-934.

Kruesi, M. J. P., Dale, J., \& Straus, S. E. (1989). Psychiatric diagnoses in patients who have chronic fatigue syndrome. Journal of Clinical Psychiatry, 50(2), 53-56.

Lane, T. J., Mathews, D., \& Manu, P. (1991). Depression and somatization in the chronic fatigue syndrome. The American Journal of Medicine, 91, 335-44.

Lane J. D., \& Wegner, D. M. (1995). The cognitive consequences of secrecy. Journal of Personality and Social Psychology, 69, 1-17.

Lanigan, S. (1991). The stigma of port-wine stains. British Journal of Hospital Medicine, $45,274-6$.

Lawrie, S. M., \& Pelosi, A. J. (1995). Chronic fatigue syndrome in the community prevalence and associations. British Journal of Psychiatry, 166, 793-797. 
Lennon, M. C., Link, B. G., Marbach, J. J., \& Dohrenwend, B. P. (1989). The stigma of chronic facial pain and its impact on social relationships. Social Problems, 36(2), 117134.

Lerner, M. (1980). The belief in a just world: A fundamental delusion. New York: Plenum Press.

Link, B. G., Cullen, F. T., Struening, E., Shrout, P. E., \& Dohrenwend, B. P. (1989). A modified labeling theory approach to mental disorders: An empirical assessment. American Sociological Review, 54, 400-23.

Link, B. G., Struening, E. L, Rahav, M., Phelan, J. C., \& Nuttbrock, L. (1997). On stigma and its consequences: evidence from a longitudinal study of men with dual diagnoses of mental illness and substance abuse. Journal of Health \& Social Behavior, 38, 177-90.

Lord, C. G., \& Saenz, D. S. (1985). Memory deficits and memory surfeits: Differential cognitive consequences for tokens and observers. Journal of Personality and Social Psychology, 49, 918-926.

Lowe, J. G. (1993). The stigma of acne. British Journal of Hospital Medicine, 49, 809-12. Lydiard, R. B., Fossey, M. D., Marsh, W., \& Ballenger, J. C. (1993). Prevalence of psychiatric disorders in patients with irritable bowel syndrome. Psychosomatics, 34(3), 229-234.

Makela, M., \& Heliovaara, M. (1991). Prevalence of primary fibromyalgia in the Finnish population. British Medical Journal, 303, 216-9.

Manu, P., Lane, T. J., \& Matthews, D. A. (1989). Somatization disorder in patients with chronic fatigue. Psychosomatics, 30(4), 388-395. 
Marbach, J. J., Lennon, M. C., Link, B. G., \& Dohrenwend. (1990). Losing face: sources of stigma as perceived by chronic facial pain patients. Journal of Behavioral Medicine, $13,583-604$.

Markowitz, F. E. The effects of stigma on the psychological well-being and life satisfaction of persons with mental illness. Journal of Health \& Social Behavior, 39, $335-47$.

McHorney, C. A., Ware, J. E. \& Raczek, A. E. (1993). The MOS 36-item short-form health survey (SF-36). II Psychometric and clinical tests of validity in measuring physical and mental health constructs. Medical Care, 31(3), 247-263.

Muzzin, L. J., Anderson, N. J., Figueredo, A. T., \& Gudelis, O. (1994). The experience of cancer. Social Science and Medicine, 38, 1201-1208.

Newberg, S. L., Smith, D. M., \& Asher, T. (2000). Why people stigmatize: toward a biocultural framework. In T. F. Heatherton, R. E. Kleck, M. R. Hebl, \& J. G. Hull (Eds.), The Social Psychology of Stigma. New York, NY: The Guilford Press.

Paulhus, D. L. (1984). Two-component models of socially desirable responding. Journal of Personality and Social Psychology, 46, 598-609.

Pinel, E. C. Stigma consciousness: the psychological legacy of social stereotypes. Journal of Personality \& Social Psychology, 76, 114-28.

Reid, U. (1997). Stigma of hair loss after chemotherapy. Paediatric Nursing, 9, 16-18.

Ridsdale, L, Robins, D., Fitzgerald, A., Jeffery, S., \& McGee, L. (1996). Epilepsy in general practice: patients' psychological symptoms and their perception of stigma. British Journal of General Practice, 46, 365-6. 
Raguram, R., Weiss, M. G., Channabasavanna, S. M., \& Devins, G. M. (1996). Stigma, depression, and somatization in South India. American Journal of Psychiatry, 153, 1043-1049.

Ryan, R., Kempner, K., \& Emlen, A. C. (1980). The stigma of epilepsy as a self-concept. Epilepsia, 21, 433-44.

Sammons, M. T., \& Karoly, P. (1987). Psychosocial variables in irritable bowel syndrome: A review and proposal. Clinical Psychology Review, 7, 187-204.

Sandler, R. S., Drossman, D. A., Nathan, H. P., \& McKee, D. C. (1984). Symptom complaints and health care seeking behavior in subjects with bowel dysfunction. Gastroenterology, 87, 314-318.

Scambler, G., \& Hopkins, H. (1990). Generating a model of epileptic stigma: the role of qualitative analysis. Social Science and Medicine, 30, 1187-94.

Scambler, G. (1984). Perceiving and coping with stigmatizing illness. In R. Fitzpatrick, J. Hinton, S. Newman, G. Scambler, \& J. Thompson. Laondon: Tavistock Publications Ltd.

Shorter, E. (1992). From Paralysis to Fatigue: A History of Psychosomatic Illness in the Modern Era. New York: Free Press.

Smart, L., \& Wegner, D. M. (2000). The hidden costs of hidden stigma. In T. F. Heatherton, R. E. Kleck, M. R. Hebl, \& J. G. Hull (Eds.), The Social Psychology of Stigma. New York: The Gilford Press.

Smythe, H. (1986). Tender points: Evolution of the fibrositis/fibromyalgia syndrome. American Journal of Medicine, 81(suppl 3A), 2-6. 
Snadden, D. \& Brown, J. B. (1992). The experience of Asthma. Social Science and Medicine, 34, 1351-1361.

Solomon, S., Greenberg, J., \& Pyszczynski, T. (1991). A terror management theory of social behavior: The psychological functions of self-esteem and cultural worldviews. In M. P. Zanna (Ed.), Advances in experimental social psychology (Vol.24, pp. 93-159). San Diego, CA: Academic Press.

SPSS 9.0. SPSS Inc. Chicago, IL.

St. Lawrence, J. S., Husfeldt, B. A., Kelly, J. A., Hood, H. V., \& Smith, S. Jr. (1990). The stigma of AIDS: fear of disease and prejudice toward gay men. Journal of Homosexuality, 19, 85-101.

Steele, L., Dobbins, J. G., Fukuda, K., Reyes, M., Randall, B., Koppelman, M., \& Reeves, W. C. (1989). The epidemiology of chronic fatigue in San Francisco. American Journal of Medicine, 105, 83S-90S.

Straus, S. E., Tosato, G., Armstrong, G., Lawley, T., Preble, O. T., Henle, W., Davey, R., Pearson, G., Epstein, J., Brus, I., \& Blaese, R. M. (1985). Persisting illness and fatigue in adults with evidence of Epstein-Barr Virus infection. Annals of Internal Medicine, $102,7-16$.

Susman, J. (1994). Disability, stigma and deviance. Social Science and Medicine, 38, 1522.

Talley, N. J., Zinsmeister, A. R., \& Melton, L J. $3^{\text {rd }}$. (1995). Irritable bowel syndrome in a community: symptom subgroups, risk factors and health care utilization. American Journal of Epidemiology, 142, 76-83. 
Thompson, W. G., Dotevall, G., Drossman, D. A., Heaton, K. W., \& Kruis, W. (1989). Irritable bowel syndrome: Guidelines for the diagnosis. Gastroenterology International, 2, 92-95.

Tobi, M., Zohar, D., Feldman-Weiss, V. Ben-Chetrit, E. Morag, A., Chowers, I., Michaeli, Y, \& Shalit, M. (1982). Prolonged atypical illness associated with serological evidence of persistent Epstein Barr Virus. Lancet, 8263, 61-64.

Toner, B. B., Kohama, E., Garfinkel, P. E., Jeejeebhoy, K. N., \& Di Gasbarro, I. (1992). Social desirability and irritable bowel syndrome. International Journal of Psychiatry in Medicine, 22, 99-103.

Wahl, O. F. (1999). Mental health consumers' experience of stigma. Schizophrenia Bulletin, 25, 467-78.

Wahl, O. F., \& Harman, C. R. (1989). Family views of stigma. Schizophrenia Bulletin, $15,131-139$

Ware, J. E. \& Sherbourne, C. D. (1992). The MOS 36-item short-form health survey (SF36). I Conceptual framework and item selection. Medical Care, 30(6), 473-483.

Warrenburg, S., Levine, J., Schwartz, G., Fontana, A., Kerns, R., Delaney, R., \& Mattson, R. (1989). Defensive coping and blood pressure reactivity in medical patients. Journal of Behavioral Medicine, 12, 407-424.

Weiner, B., Perry, R. P., \& Magnusson, J. (1988). An attributional analysis of reactions to stigmas. Journal of Personality and Social Psychology, 55, 738-748.

Wegner, E. M., \& Erber, R. (1992). The hyperaccessibility of suppressed thoughts. Journal of Personality and Social Psychiatry, 63, 903-912. 
Wegner, D. M., Erber, R., \& Zanakos, S. (1993). Ironic processes in the mental control of mood and mood-related thought. Journal of Personality and Social Psychology, 65, 1093-1104.

Weiss, M. G., Doongaji, D. R., Siddartha, S., Wypij, D., Pathare, S., Bhatawdekar, M., Bhave, A., Sheth, A., \& Fernandes, R. (1992). The Explanatory Model Interview Catalogue (EMIC): Contribution to cross-cultural research methods from a study of leprosy and mental health. British Journal of Psychiatry, 160, 819-830.

Wessely, S., Chalder, T., Hirsch, S., Wallace, P., \& Wright, D. (1997). The prevalence and morbidity of chronic fatigue and chronic fatigue syndrome: a prospective primary care study. American Journal of Public Health, 87, 1449-55.

Wessely, S., Nimnuan, C., \& Sharpe, M. (1999). Functional somatic syndromes: one or many? The Lancet, 354, 936-39.

Wessely, S., \& Powell, R. (1989). Fatigue syndromes: A comparison of chronic "postviral" fatigue with neuromuscular and affective disorders. Journal of Neurology, Neurosurgery and Psychiatry, 52: 940-948.

White, K. P., Speechley, M., Harth, M., \& Ostbye, T. (1999). The London fibromyalgia epidemiology study: the prevalence of fibromyalgia syndrome in London, Ontario. Journal of Rheumatology, 26, 1570-6.

White, K. P., Speechley, M., Harth, M., \& Ostbye, T. (1999b). Comparing self-reported function and work disability in 100 community cases of fibromayalgia syndrome versus controls in London, Ontario: the London Fibromyalgia Epidemiology Study. Arthritis \& Rheumatism, 42, 76-83. 
Whitehead, W. E., Bosmajian, L., Zonderman, A. B., Costa, P. T., \& Schuster, M. M. (1988). Symptoms of psychologic distress associated with irritable bowel syndrome. Gastroenterology, 95, 709-714.

Whitehead, W. E., Engel, B. T., \& Schuster, M. M. (1980). Irritable bowel syndrome: Physiological differences between diarrhoea-predominant and constipationpredominant patients. Digestive Diseases and Sciences, 25, 404-413.

Whitty, C. J. (1999). Erasmus, syphilis, and the abuse of stigma. Lancet, 354, 2147-8.

Wills, T. A. (1981). Downward comparison principles in social psychology.

Psychological Bulletin, 90, 245-271.

Willis, R. (1994). Illness and Social Relations: Issues in the Sociology of Health Care. Sidney, Australia: Allen \& Unwin.

Wolfe, F. (1986). Development of criteria for the diagnosis of fibrosits. American Journal of Medicine, 81(suppl 3A), 99-106.

Wolfe, F., Anderson, J. Jarkness, D., Bernett, R. M., Caro, X. J., Goldenberg, D. L., Russell, I. J., \& Yunus, M. B. (1997). Work and disability status of persons with fibromyalgia. Journal of Rheumatology, 24, 1171-8.

Wolfe, F., \& Cathey, M. A. (1983). Prevalence of primary and secondary fibrositis. Journal of Rheumatology, 10, 965-968.

Wolfe, F., \& Cathey, M. A. (1985). The epidemiology of tender points: A prospective study of 1520 patients. Journal of Rheumatology, 12, 1164-1168.

Wolfe, F., Ross, K., Anderson, J., Russell, I., J. \& Hebert, L. (1995). The prevalence and characteristics of fibromyalgia in the general population. Arthritis \& Rheumatism, 38, $19-28$. 
Woodward, R. (1993). It's so strange when you stay sick: the challenge of chronic fatigue syndrome. Dissertation. Australian National University.

Yamada, S., Caballero, J., Matsunaga, D. S., Agustin, G., \& Magana M. (1999). Attitudes regarding tuberculosis in immigrants from the Philippines to the United States. Family Medicine, 31, 477-82.

Yunus, M. B., Masi, A. T., Calabro, J. J., Miller, K. A., \& Feigenbaum, S. L. (1981). Primary fibromyalgia (fibrositis): Clinical study of 50 patients with matched normal controls. Seminars in Arthritis and Rheumatism, 11(1), 151-171. 


\section{APPENDIX 1: ATTITUDES OF OTHERS}

The following are a series of statements regarding feelings and attitudes that people hold towards health problems like yours. We would like you to indicate whether you strongly disagree, disagree, agree or strongly agree with each statement. There are no right or wrong answers. Circle the response that best indicates how you feel.

$\begin{array}{lcc}\text { STRONGLY DISAGREE } & \text { AGREE } & \text { STRONGLY } \\ \text { DISAGREE } & \text { AGREE }\end{array}$

$\begin{array}{llll}\text { SD } & \text { D } & \text { A } & \text { SA }\end{array}$

1. If neighbors, colleagues and others knew someone with health problems like mine they would think less of that person.

SD D A SA

2. If neighbors, colleagues and others knew someone with health problems like mine, they would think less of the family of that person.

SD D A SA

3. One problem with having health problems like mine is that people don't believe that you really have the symptoms that you say you do.

SD D A SA

4. If others knew, that a person had health problems

SD D A SA like mine, it would be more difficult for that person to get married.

5. Most people who have health problems like mine think less of themselves.

SD D A SA

6. Most people believe that a person with health problems like mine is just as emotionally stable as the average person.

SD D A SA

7. I rarely feel the need to hide the fact that I have seen a doctor for my health problems.

SD D A SA

8. Health problems like mine might cause people to have difficulties in their marriages.

SD D A SA

9. I have sometimes wished that people could see my symptoms.

SD D A SA 
10. Most people would willingly accept a person with health problems like mine as a close friend.

SD D A SA

11. People have a way of making a person with health problems like mine feel ashamed or embarrassed.

SD D A SA

12. Having health problems has made me feel very different from other people.

SD D A SA

13. Many people assume that a person who suffers from health problems like mine has a deep seated psychological problem as well.

SD D A SA

14. I have found that it is a good idea to help the people close to me understand what my treatment involves.

SD D A SA

15. When people learn that you have been treated for health problems like mine, they begin to search for flaws in your personality.

SD D A SA

16. Most employers will pass over the application of a person with health problems like mine in favor of another applicant.

SD D A SA

17. There is a part of me that only other people who have experienced health problems like mine can understand.

SD D A SA

18. People have a way of associating the occurrence of health problems like mine with psychiatric difficulties.

SD D A SA

19. I often feel totally alone with my symptoms.

SD D A SA

20. Most people have no idea what it is like to have health problems like mine.

SD D A SA

21. Many people assume that having health problems like mine is a sign of personal weakness.

SD D A SA

22. People often try to avoid a person with health problems like mine.

SD D A SA

23. Most employers will hire a person with health problems like mine if he or she is qualified for the job.

SD D A SA 


\section{APPENDIX 2: SCL-90 Depression Sub-scale, modified.}

Please tell me on how many separate days in the last month you have had the following symptoms:

\begin{tabular}{|cccc|}
\hline $\begin{array}{c}\text { O days } \\
\text { None }\end{array}$ & $\begin{array}{c}\text { 1-6 days } \\
\text { Occasionally }\end{array}$ & $\begin{array}{c}7-14 \text { days } \\
\text { Often }\end{array}$ & $\begin{array}{c}\text { more than 14 days } \\
\text { Very Often }\end{array}$ \\
\hline
\end{tabular}

1. had a feeling of being trapped or caught.

2. cried easily $.00 \quad 1-6 \quad 7-14 \quad 14+$

3. felt hopeless about the future........................... $1-6 \quad 7-14 \quad 14+$

4. felt no interest in things................................... $1-6 \quad 7-14 \quad 14+$

5. blamed yourself for things................................ $1-6 \quad 7-14 \quad 14+$

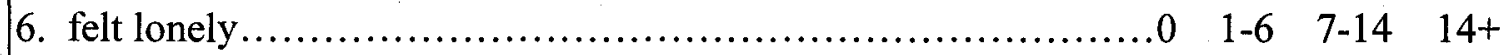

7. had feelings of worthlessness..............................

8. felt low in energy or slowed down.......................... $1-6 \quad 7-14 \quad 14+$

9. felt everything is an effort................................. $1-6 \quad 7-14 \quad 14+$

10. been worrying too much about things.......................

11. felt blue................................................ $1-6 \quad 7-14 \quad 14+$

12. had thoughts of ending your life............................

13. experienced loss of sexual interest or pleasure................. $1-6 \quad 7-14 \quad 14+$ 